\title{
Marketing control in international headquarters-subsidiary working relationships of industrial goods firms: the role of environmental context
}

\section{Lukas Isenberg $^{1}$ (D) $\cdot$ Susanne Kreiter ${ }^{2} \cdot$ Roland Helm $^{2} \cdot$ Christian Schmitz $^{1}$}

Accepted: 20 December 2021 / Published online: 8 January 2022

(c) The Author(s) 2022

\begin{abstract}
The use of marketing and sales control mechanisms is a core management activity for multinational corporations. However, research on controlling marketing and sales of international subsidiaries is scarce. In particular, the influence of a firm's economic and cultural environment on different control mechanisms has not been thoroughly examined yet. In attempting to fill these gaps, we build on Jaworski's (J Mark 52:23-39, 1988) framework from a subsidiary perspective on marketing and sales controls, applied by the headquarters of medium-sized industrial goods corporations. Through a rival model analysis, we determine the impact of the local environmental context on marketing and sales control types exerted by headquarters on subsidiaries located in foreign countries. To analyze the proposed model, this study deploys survey data of 184 subsidiaries from different industries and different European countries with headquarters in Switzerland. The results show that while environmental factors influence the marketing and sales control configurations, the effectiveness of marketing and sales controls is not contingent on environmental factors.
\end{abstract}

Keywords Marketing control $\cdot$ International marketing $\cdot$ Medium-sized corporations $\cdot$ Industrial goods $\cdot$ Sales management $\cdot$ Sales control

Lukas Isenberg

lukas.isenberg@rub.de

Susanne Kreiter

skreiter@web.de

Roland Helm

sigm@ur.de

Christian Schmitz

smd@rub.de

1 University of Bochum, Bochum, Germany

2 University of Regensburg, Regensburg, Germany 


\section{JEL Classification M16 · M31}

\section{Introduction}

A strong international presence has become a strategic pillar for many companies. For example, in 2017, General Electric served customers in over 180 countries worldwide and generated $62 \%$ of its revenues outside its home market the USA. Peri, a leading manufacturer of formwork and scaffolding technology, generates even $90 \%$ of its sales outside its home market Germany. The World Investment Report 2020 estimates that more than $50 \%$ of employees of multi-national corporations (MNCs) are located in foreign subsidiaries (UNCTAD 2020).

In order to align marketing and sales activities around the world with the corporate strategy and to maintain effective relationships with subsidiaries beyond national borders, effective control systems are crucial for MNCs (Aulakh et al. 1996; Rao et al. 2007; Zhang et al. 2003). However, international subsidiaries operate in different economic and cultural environments than their headquarters. Therefore, international subsidiaries often require different management practices and organizational structures than those applied by and in the headquarters (Rondinelli et al. 2001). This increases the complexity of controlling marketing and sales units of international subsidiaries, posing a major challenge for designing effective control systems in MNCs' (Rosenzweig and Singh 1991).

Extant research discussed the question, how headquarters can adapt their general management practices to local boundary conditions of international subsidiaries (e.g., Bloom et al. 2003; Kumar et al. 2013; Nohria and Ghoshal 1994). However, research on controlling marketing and sales of international subsidiaries is scarce. In particular, the influence of a firm's economic and cultural environment on the effectiveness of different control mechanisms has not been thoroughly examined yet.

Jaworski (1988) proposes a theory of formal marketing controls, in which he defines them as a system of methods, procedures, and devices that marketing managers use to ensure compliance with marketing policies and strategies (Park and Zaltman 1987), as well as a related framework that integrates the environmental context, controls, and their consequences. Several studies have investigated relationships within this framework in a national marketing and sales context (e.g., Cravens et al. 2004; Luo et al. 2011; Miao and Evans 2013). Although the management of international marketing and selling organizations has received attention by extant marketing research (e.g., Hill et al. 1991; Magnusson et al. 2014), Jaworski's (1988) framework has not been thoroughly analyzed in an international marketing and sales context so far. Therefore, with respect to the increasing internationalization in many companies, this paper seeks to answer three salient research questions, detailed below:

First, how do environmental factors shape the configuration of marketing and sales control systems in MNCs? International working relationships are characterized by greater complexity and uncertainty than domestic collaborations (Klein et al. 1990; Rosenbloom 1999). Yet, extant research examines intraorganizational relationships predominantly in national sales organizations. Therefore, it remains 
unclear, how environmental factors shape the configuration of marketing and sales control systems in MNCs. This paper helps to understand how MNCs apply marketing and sales controls in international headquarters-subsidiaries relationships. The results of our study show that while MNCs in dynamic and uncertain markets refrain from using output control, a cultural environment characterized by strong ambitions for performance and growth promotes the use of output control.

Second, how do marketing and sales control mechanisms affect economical and psychological outcomes in international subsidiaries? Local marketing and sales units have a vital role in MNCs. They not only provide access to desired target markets, but also implement relevant corporate marketing strategy locally, and maintain close relationships to customers (Arnold 2000). Therefore, understanding the effectiveness of marketing and sales controls in an international headquarters-subsidiaries relationship is of major importance. However, previous research on managing international headquarters-subsidiaries relationships has largely focused on the headquarters' perspective. Thus, little is known about how marketing and sales controls by headquarters affect economical and psychological outcomes in international subsidiaries. This study examines the relationship satisfaction of foreign subsidiaries as well as local performance outcomes. The results of our study show a positive effect of output control on satisfaction with the relationship with the headquarters, but no significant direct effects of process control on performance and psychological outcomes.

Third, how do environmental factors influence the effectiveness of marketing and sales controls in international headquarters-subsidiary relationships? Transnational working relationships do not exist in a vacuum but rather interact with contextual or environmental factors that potentially moderate the relationship between controls and their consequences (Johnson et al. 1993, 1996). Environmental variables are much more relevant in transnational than in domestic relationships (Kim and $\mathrm{Oh}$ 2002). However, previous research has overly neglected to analyze the contingent effects of environmental factors on the effectiveness of marketing and sales controls. Therefore, it remains unclear, how headquarters may adapt their marketing and sales control mechanisms to different international boundary conditions. This study addresses this research gap by analyzing the effectiveness of sales control strategies in different local contexts. The results of our study show that environmental factors have no significant impact on the effectiveness of marketing and sales control mechanisms, indicating that marketing and sales controls are rather robust against environmental factors.

In attempting to fill these gaps, we build on Jaworski's (1988) framework from a subsidiary perspective on marketing and sales controls. Through a rival model analysis, we determine the impact of environmental dimensions on control types exerted by headquarters on selling units located in foreign countries. To analyze the proposed model, this study deploys survey data of 184 subsidiaries from different industries and different European countries with headquarters in Switzerland. We test the model using structural equation modeling.

In the next section, we review existing work on environmental contexts, marketing control, and outcome variables. After we describe our methods and samples, we discuss the results of a quantitative investigation of Jaworski's and alternative 
conceptual models and compare the models' quality afterwards. Finally, we summarize the key findings and suggest implications for the management of international organizations, as well as for further research efforts.

\section{Theoretical background}

Marketing involves a series of activities, yet most literature focuses on the planning aspects rather than the implementation of marketing programs (Bonoma 1985) or the control of marketing personnel (Anderson and Oliver 1987; Jaworski 1988). Even when such front-end activities are well designed, their expected benefits can be easily offset by poor implementation and control (Jaworski and MacInnis 1989). Therefore, it is important to understand control issues in marketing and their effects on working relationships.

Formal marketing and sales control systems are generally written and management-initiated rules and procedures for monitoring, evaluating and compensating employees (Anderson and Oliver 1987). They can either be implemented as output or process-based controls. Output control solely evaluates the sales results and compares them against performance goals. Output control thus features performance standards, which are clearly set and monitored, with their results carefully evaluated (Challagalla and Shervani 1996; Jaworski 1988). The involvement of the management in directing employees is rather small, since employees are self-responsible for fulfilling their performance goals (Miao and Evans 2013).

In contrast, process control focuses on individual behavior and its likelihood of leading to certain outcomes and/or activities, e.g., activities regarding customer relationships. It aims at influencing "the means to achieve desired aims" (Jaworski 1988 p. 26). Process control requires clearly defined processes and an active involvement of the management in directing and evaluating employees (Miao and Evans 2013).

Extant research identified a large number of determinants of marketing and sales control systems. Most of the empirical studies have focused on internal factors, such as sales force and sales task related characteristics. Despite a strong theoretical foundation, however, empirical research on external determinants of marketing and sales controls and their different types is scarce. Some studies address external environmental characteristics, such as market uncertainty, sales volatility, or psychic distance, as antecedents of marketing and sales controls (e.g., Bello and Gilliland 1997; Krafft 1999). However, these factors still have received less attention than organizational and personal characteristics (e.g., Krafft 1999; Jaworski et al. 1993; Ramaswami 2002). An analysis of environmental effects on international selling units thus demands a more comprehensive, multidimensional approach to the environment.

While several marketing and sales control frameworks (e.g., Anderson and Oliver, 1987; Challagalla and Shervani 1996) rather focus on differentiating various control types, Jaworski (1988) provides a rather holistic framework on marketing and sales control mechanisms. Jaworski (1988) argues that in order to understand the complexity of control mechanisms, it is critical to consider not only different control types, but the environmental context as well as different outcomes of control mechanisms simultaneously (Jaworski 1988). In particular, he proposes a direct 

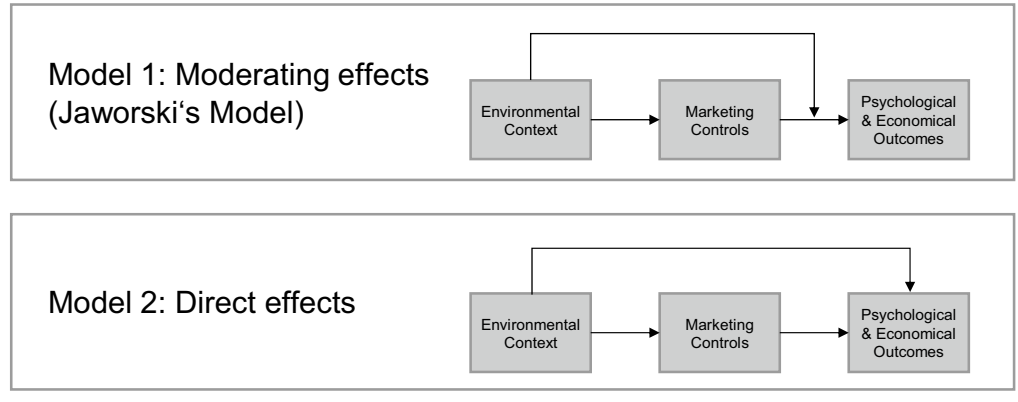

Model 3: Basic effects

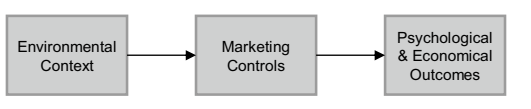

Fig. 1 Competitive models of the relationship of environmental context, control, and resulting outcomes

effect of the environmental context on the emphasis of control mechanisms as well as a moderating effect of environmental context on the relationship between control mechanisms and its consequences (see Model 1, Fig. 1). However, this moderating effect has yet not been supported empirically (Atuahene-Gima and Li 2006; Gencturk and Aulakh 1995; Jaworski and MacInnis 1989). Instead, research reveals contrary propositions and results that provide empirical support only for a direct effect of the environmental context on individual and organizational outcomes (e.g., Leonidou et al. 2002; Panagopoulos and Avlonitis 2010; Ryu et al. 2008), as Model 2 in Fig. 1 indicates. To the best of our knowledge, the model of context, control, and resulting effects have not been tested empirically. Thus, by building on the Jaworski (1988) model we attempt to clarify the role of the environmental context in international headquarters-subsidiary relationships by considering the multidimensional environment. Table 1 provides an overview of previous research on sales control systems.

\section{Conceptual model and hypotheses}

We offer hypotheses regarding the predicted relations within the model. We propose that marketing and sales controls have a positive influence on the outcomes of international headquarters-subsidiary relationships. We distinguish psychological outcomes (satisfaction with the relationship with the headquarters) from economical outcome (overall selling performance relative to the businesses' largest competitor). Furthermore, we propose moderating effects of environmental factors on the effect of marketing and sales controls on psychological and economical outcomes. Moreover, we propose direct effects of the environmental 


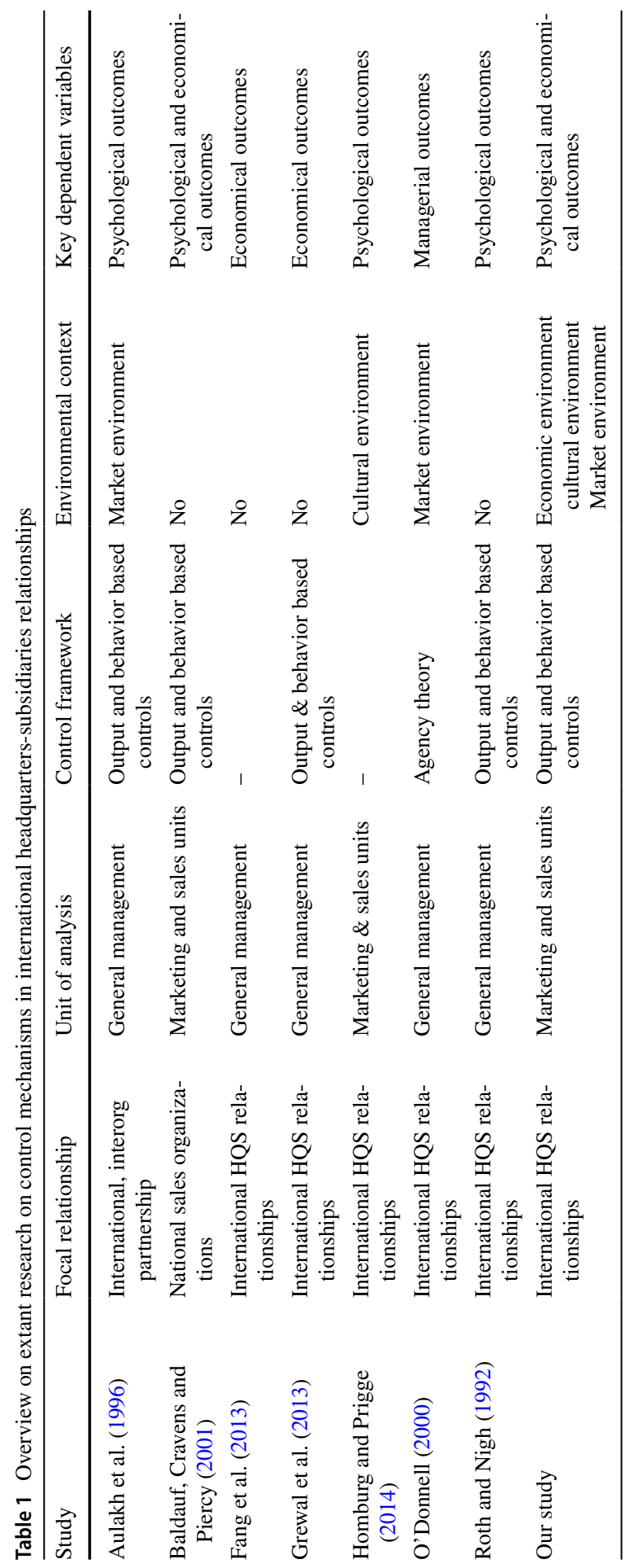




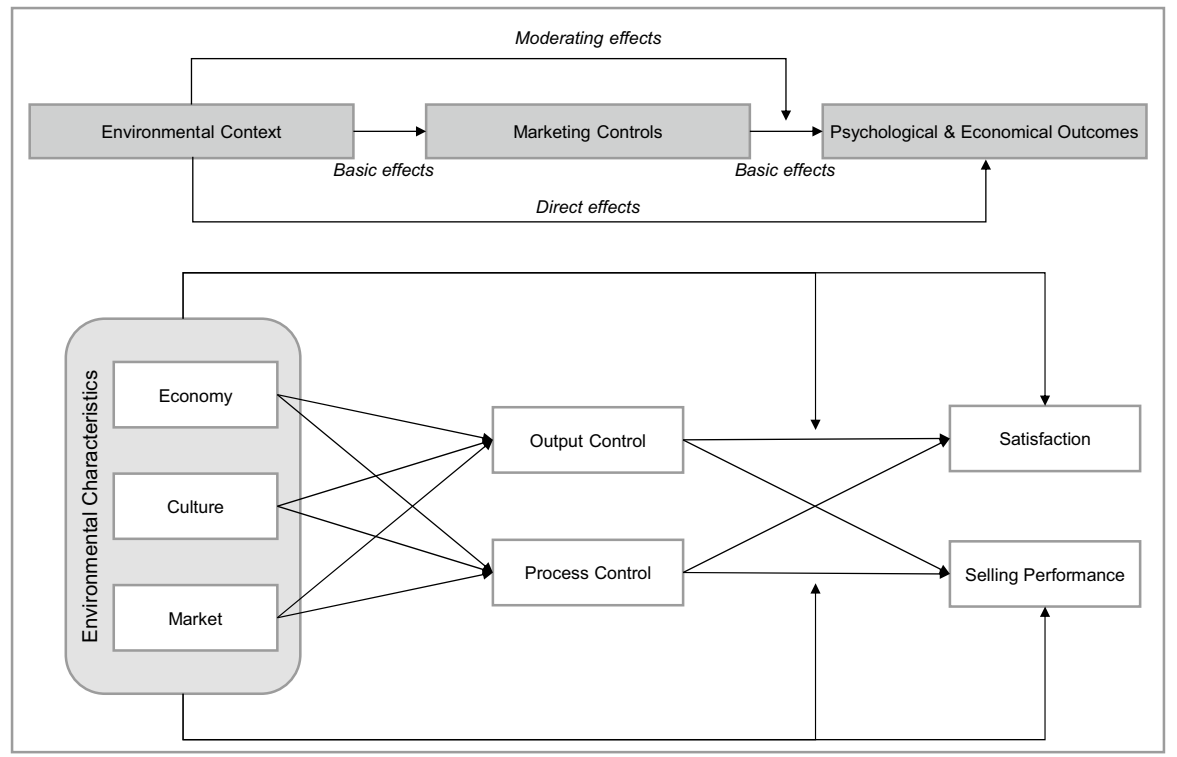

Fig. 2 Proposed framework

dimensions on the marketing and sales controls and psychological and economical outcomes. Figure 2 serves as a framework to summarize the relationships of the variables.

\subsection{The subsidiary perspective and headquarters marketing controls}

Formal controls aim to influence the probability that employees will behave in ways that support the firm's stated managerial objectives (Eisenhardt 1985; Jaworski 1988; Ouchi 1979). Formalization makes one party's behavior more observable to the other, promoting transparency and accountability (Luo et al. 2011). Output and process controls (Jaworski 1988) reflect traditional strategies used by manufacturers to coordinate their marketing and sales activities unilaterally (Weitz and Jap 1995).

Managers often prefer output controls, because the evaluation process is feasible, clear, and comprehensible (Cravens et al. 2004). Output-based control leaves selling units independent of the manufacturer in their decision making and implementation of activities and processes, which means they can respond quickly and flexibly to changes in their unique market environments (Bello and Gilliland 1997). According to goal theory (Locke and Latham 1990), clear outcome goals motivate people to focus on behaviors that help them to achieve desired results. Salespeople can easily identify and evaluate the objectives of the corporation and balance them against their own attitudes in order to adjust their behavior accordingly (Morris and Steers 1980). Moreover, output controls allow 
salespeople a high degree of autonomy in performing their selling task (Anderson and Oliver 1987), which was found to have a positive effect on job satisfaction (Brown and Peterson 1993). Challagalla and Shervani (1996) also find that the transfer of output information can reduce the role ambiguity, resulting in higher salespeople's satisfaction.

Extant sales and marketing research indicates that output control has a direct effect on sales performance (e.g., Bello and Gilliland 1997; Miao et al. 2007; Miao and Evans 2012). Output control signals the manufacturers' most important performance goals and facilitates the identification of performance goals that interest both parties. Agreement between the manufacturer and seller on such goals is even vital for intraorganizational relationship performance (Celly and Frazier 1996). As a result, the salesperson's motivation to achieve the determined standards increases (Oliver and Anderson 1994). A clear, comprehensible definition of performance goals facilitates a clearer focus on the main tasks, efficient processes, and search for relevant information to achieve the goals (Kohli et al. 1998). Because the achievement of high outcomes represents a common goal of headquarters and subsidiaries, output control should enhance unit-level satisfaction and selling performance. Therefore, we hypothesize:

Hypothesis 1: The higher the degree of output control, the higher the (a) satisfaction with the relationship with the headquarters and (b) selling performance of the selling unit.

In contrast to output control, process control describes a behavior-based form of control that targets the behaviors of selling units, which may lead to desired performance ends and that also are consistent with company goals (Anderson and Oliver 1987; Jaworski 1988). Compared with output control, the manufacturer intervenes earlier with process controls, resulting in a higher input of resources and attention from the manufacturer (Bello and Gilliland 1997). Salespeople do not confront desired targets but rather are guided and supported by relevant information that enables their correct and successful behavior. Previous research indicates a positive relationship between process control and selling performance. For example, Dwyer and Oh (1987) found a positive influence of the degree of formalization of rules and procedures on the satisfaction with the relationship with the headquarters (see also Dwyer 1980). Also, Challagalla and Shervani (1996) find that salespeople's satisfaction improves with the transfer of activity information. Similarly, Jaworski and Kohli (1991) found that satisfaction with the supervisor is likely to increase due to behavioral-based feedback, which in turn creates a clear picture of expectations. Therefore, the implementation of process controls should enhance psychological and economical outcomes.

Hypothesis 2: The higher the degree of process control, the higher the (a) satisfaction with the relationship with the headquarters and (b) selling performance of the selling unit. 


\subsection{Local context and degree of control}

The analysis of the environment in which a sales unit works is highly complex and interconnected (Fahey and Narayanan 1986; Miller and Friesen 1983), considering its multidimensional character (Duncan 1972). The control mechanisms of the manufacturer should be adapted to the environmental contingencies faced by the selling unit. To do so, headquarters might decompose the local environment into three local market sub-environments (Bourgeois 1980): economic, cultural, and market environment.

\subsubsection{Economic environment}

The implementation of marketing and managerial policies should always be adapted to local context factors (Deshpande and Webster 1989). In line with this recommendation, we examine the direct effect of the local environmental context on the two control types. The economic environment helps determine the attractiveness of foreign markets (Evans and Mavondo 2002). The wealth of a society implies higher demand for goods and services, which offers a basis for high growth potential (Evans and Mavondo 2002). Although high growth potential markets are attractive (Burke 1984), they also appeal to competitors, such that competitive intensity tends to be greater in these markets (Gencturk and Aulakh 1995). Competitive intensity gives firms an incentive to monitor the market closely and respond quickly and flexibly to competitors' moves (Wernerfelt and Karnani 1981). Output control enables companies to address these two requirements simultaneously. On the one hand, output control allows for greater flexibility in the sales unit's activities (Bello and Gilliland 1997) due to higher degrees of autonomy. On the other hand, output control enables companies to determine specific and measurable outcome goals. In contrast, process control rather limits autonomy due to rather strict guidelines on behaviors and actions for achieving desired outcomes (Jaworski 1988). Therefore, we hypothesize a positive relationship between the level of economic development and the degree of output control, but a negative relationship between economic development levels and the degree of process control.

Hypothesis 3: The higher the level of economic development, (a) the higher the degree of output control, and (b) the lower the degree of process control.

\subsubsection{Cultural environment}

In international contexts and cultural environments, a consideration of the influences of national culture is inevitable. National culture refers to shared value systems, customs, and religions; researchers emphasize national culture as an important antecedent of marketing and management control (Desphande and Webster 1989; Lebas and Weigenstein 1986), and the success of any international marketing strategy depends on its conformity with the values and beliefs of employees situated in various host countries (Desphande and Webster 1989). Cultural characteristics further affect 
expectations and evaluations of external and internal relationships. Such relationship evaluations depend on the expectations of the parties involved, regarding their own and counterparts' behavior.

Hofstede (1980) developed a widely adopted approach for conceptualizing and measuring cultural characteristics. Depending on the research context, the five dimensions ${ }^{1}$ discovered by Hofstede (1983) vary in their degree of importance. Hofstede suggests that the degree of masculinity and femininity in a society is a strong indicator for comparing cultural values and individual behaviors. Previous management research has confirmed the important influence of the masculinity/femininity dimension on individual behaviors (Taras et al. 2010), for establishing and maintaining internal business relationships (Batonda and Perry 2003; Hoppe 1998; Shackleton and Ali 1990; Tang and Koveos 2008) as well as on steering employees in international subsidiaries (Merchant et al. 2011). In cultures with a high degree of masculinity, values such as materialistic success, performance orientation, assertiveness and competitiveness are prevailing. In contrast, cultures with a low degree of masculinity (feminine cultures) value warm personal relationships, cooperativeness, and solidarity (Hofstede 1994).

Beliefs about effective control structures often become embedded in the way the firm does things, suggesting a relationship between culture and control mechanisms (e.g., Bello and Gilliland 1997; Calori et al. 1994; Redding and Pugh 1986; Snodgrass and Grant 1986). Masculine cultures stress material success and instrumentality with strong ambitions for performance and growth, so subsidiaries embedded in a more masculine environment are likely to cope better with clear outcome targets and expectations, as realized by output control. This type of control meets their interests and gives them independence in their decision making. Morris and Steers (1980) also stress that output control makes it easier for employees to identify and evaluate corporate objectives and balance them with their own attitudes. In contrast, cultures with low degrees of masculinity are characterized by a rather relational orientation, which requires more frequent interactions (Hofstede 1994). Therefore, subsidiaries situated in less masculine contexts might prefer more guidance over their actions and additional support from headquarters to achieve the expected results. Since process control focusses on a rather relational exchange between headquarters and subsidiaries, applying this control mechanism in cultures with low degrees of masculinity may address the need for relational exchange more adequately and, therefore, may be more prevalent in less masculine cultures. Therefore, we hypothesize:

Hypothesis 4: The higher the masculinity, (a) the higher the degree of output control, and (b) the lower the degree of process control.

\footnotetext{
1 Namely these dimensions are: Power Distance, Uncertainty Avoidance, Masculinity vs. Femininity, Individualism vs. Collectivism, Long vs. Short Term Orientation.
} 


\subsubsection{Market environment}

From the headquarters' point of view, market uncertainty adversely affects its ability to predict potential outcomes and define performance-based standards (Bello and Gilliland 1997). Although the environment cannot be influenced by the sales unit, it may affect outcomes and even prevent the achievement of performance goals. According to the sales unit, the implementation of marketing and sales controls based solely on output threatens a transfer of all the performance risk to the salespeople (Atuahene-Gima and Li 2002). Consequently, sales efforts decline to a minimum, because the results of marketing-related activities are uncertain and not visible to the manufacturer (Celly and Frazier 1996). Moreover, Govindarajan (1984) provides evidence that formal performance evaluations are more common in environments that face less uncertainty. Therefore, we hypothesize:

Hypothesis 5: The higher the market uncertainty, (a) the lower the degree of output control, and (b) the higher the degree of process control.

\subsection{Local context and organizational effects}

\subsubsection{Economic environment}

The development level of the economic environment might influence evaluations of business relationships. For example, a higher standard of living tends to be related to greater technological development and advanced infrastructure (Desai 1991). These features all support and facilitate business operations within a country, which may influence the expectations of a foreign subsidiary towards the business relationship with its focal manufacturer, e.g., regarding high levels of professionalization or open and frequent communication. Higher environmental standards in a country should heighten these relationship expectations. Consequently, the likelihood that a manufacturer fails to meet high expectations or satisfy the foreign selling unit increases with a high level of economic development. Therefore, selling units in more advanced countries might express less satisfaction with the headquarters-subsidiary relationship than selling units operating in less advanced countries.

In addition to these psychological outcomes, we predict a direct effect of the environment on economic performance. Indicators such as economic stability, demand for goods and services, and a high level of infrastructure facilitate the unit's operations and business transactions, improving its performance (Evans and Mavondo 2002). Therefore, we hypothesize a positive relationship between the economic environment and selling performance.

Hypothesis 6: The higher the economic development, (a) the lower satisfaction with the relationship with the headquarters, and (b) the higher the selling performance of the sales unit. 


\subsubsection{Cultural environment}

Previous research indicates that subsidiaries' satisfaction with the relationship with the headquarters can be explained by expectation gaps between subsidiaries and headquarters. Expectation gaps are "differences in perception between the headquarters and a subsidiary concerning the management processes" (Chini et al. 2005, p. 146). Higher expectation gaps were found to have a negative effect on a subsidiary's satisfaction. Expectation gaps can be decreased if subsidiaries and headquarters are willing to share information frequently (Asakawa 2001). Since rather feminine cultures are characterized by higher degrees of cooperativeness and a focus on relationships, the information flow between headquarters and subsidiaries may be more efficient, which may reduce the expectation gap and lead to a higher satisfaction with the relationship with the headquarters.

Finally, prior literature indicates that the national culture of a subsidiary's location has a crucial impact on business performance (e.g., Lindholm 2000; Mascarenhas 1982). Due to the focus on materialistic success, performance orientation, assertiveness and competitiveness, employees working in more high masculine cultures display more ambition for performance and growth (Hofstede 1983). This may be especially relevant for sales jobs, as they are often characterized by rather selfresponsible tasks with a strong focus on performance (Katsikeas et al. 2018). Extant research shows that competitiveness and performance orientation lead to higher selfset goals and higher effort, which is also likely to result in higher selling performance (e.g., Brown and Peterson 1994; Brown et al. 1998; Krishnan et al. 2002). Moreover, Kohli et al. (1998) showed that performance orientation has a positive influence on selling performance. Therefore, we hypothesize:

Hypothesis 7: The higher the masculinity, (a) the lower the satisfaction with the relationship with the headquarters, and (b) the higher the selling performance of the sales unit.

\subsubsection{Market environment}

Environmental uncertainty already has been linked to organizational structures (Jaworski 1988); market uncertainty also may be influential by relating to the difficulties associated with monitoring trends, estimating the stability of the industry volume, and making accurate sales forecasts (Jaworski 1988; Ryu and Eyuboglu 2007). Especially in international settings, it is critical to focus on market uncertainty, which has a strong influence on organizational success (Leonidou et al. 2002).

Insecure market conditions require a more extensive collection of relevant information and detailed market analyses (Leblebici and Salancik 1981) timeconsuming activities. Ryu et al. (2008) empirically demonstrate the negative relation between environmental uncertainty and satisfaction in the sales organization. Furthermore, when industry volumes and sales forecasts are difficult to monitor or evaluate, selling operations cannot be implemented efficiently, such that inventory and cost problems lead to the inability to achieve specified results or required 
outcomes (Ryu and Eyuboglu 2007). Therefore, market uncertainty may affect the psychological and economical outcomes of a selling unit. In general, we propose a direct effect of the environment on psychological and economical outcomes at the selling unit level. Therefore, we hypothesize:

Hypothesis 8: The higher the market uncertainty, (a) the lower the satisfaction with the relationship with the headquarters, and (b) the lower the selling performance of the sales unit.

Previous research has shown that the control-performance relationship does not exist in a vacuum but instead relates to various internal and external factors (Atuahene-Gima and Li 2006; Fang et al. 2005; Jaworski 1988; Sahadev 2008). Therefore, we assume that the effectiveness of control systems may vary depending on cultural, economic and market environment (Chen et al. 2015; Chirkov et al. 2003). In line with Jaworski (1988), we argue that the more congruent the control system is with the requirements of the economic, cultural and market environment, the more effective is the control mechanism.

Since subsidiaries in rather advanced economic environments may require higher levels of autonomy, we expect that high levels of HDI strengthen the positive effect of output control on psychological and economical outcomes and weaken the positive effect of process control on psychological and economical outcomes.

Moreover, since cultures with higher levels of masculinity are characterized by higher levels of performance orientation, clearly defined outcome goals may be more effective in these cultural environments. Therefore, we argue that higher levels of masculinity strengthen the positive effect of output control on psychological and economical outcomes and weaken the positive effect of process control on psychological and economical outcomes.

Finally, since clear performance goals are more difficult to define under conditions of high market uncertainty, output control may be less effective in situations of high market uncertainty. Therefore, we argue that high levels of market uncertainty weaken the positive effects of output control on psychological and economical outcomes and strengthen the positives effect of process control on psychological and economical outcomes. Therefore, we hypothesize:

Hypothesis 9: High levels of economic development (a) strengthen the positive effects of output control on psychological and economical outcomes and (b) weaken the positive effects of process control on psychological and economical outcomes.

Hypothesis 10: High levels of masculinity (a) strengthen the positive effects of output control on psychological and economical outcomes and (b) weaken the positive effects of process control on psychological and economical outcomes.

Hypothesis 11: High levels of market uncertainty (a) weaken the positive effects of output control on psychological and economical outcomes and (b) strengthen the positive effects of process control on psychological and economical outcomes. 


\section{Methodology}

\subsection{Data collection and sample structure}

We developed a survey instrument, containing original measures from prior literature. With two pretests, we ensured that the questionnaire could be comprehended by marketing and sales practitioners and elicited adequate responses. First, 21 marketing and sales managers from an international, medium-sized corporation located in Switzerland agreed to fill out the survey and indicate any problematic or unclear formulations. Some minor alternations followed their comments. Second, the revised questionnaire underwent evaluation by a team of seven experts from the industrial goods sector, including high-level managers and specialized consultants. Other than some minor wording-related suggestions, the second pretest indicated that the survey instrument was well understood and could easily be filled out by participants.

We sent the final version of the survey instrument to corporate key informants, as recommended by Kumar et al. (1993). All headquarters were located in Switzerland. This was due to three reasons. First, we searched for companies with a strong international presence, which applies to Switzerland to a great extent. Second, due to our large network of companies in Switzerland, we were able to motivate several companies providing support for our study. Third, by focusing on only one country of participating headquarters, we were able to eliminate the influence of potential cultural differences of various headquarters' origin countries (Roth and Nigh 1992).

The participating sales organizations provided basic metals, fabricated metal products, machinery and equipment, and transportation equipment, as defined by the NACE (Classification of Economic Activities in the European Community) industry categories 27, 28, 29, 31, 34, and 35. Because this study focuses on the relationship between a foreign selling unit and its manufacturing headquarters, the ideal key informants were managing directors and sales and marketing directors of foreign subsidiaries involved in transnational relationships. To identify relevant key informants in each organization, we approached manufacturers' headquarters and asked them to provide the names and contact data for potential informants in European subsidiaries, in charge of local marketing and sales activities (Futrell and Parasuraman 1984). We solicited only one potential respondent per manufacturer, so that a broader set of organizations was included. The industrial manufacturers identified 1,405 potential key informants at foreign subsidiaries. We first announced our study to these key informants via e-mail. One week later, we sent the standardized survey instrument through the same route. Potential participants were offered a management summary of the survey results and the chance to win a popular management book in a raffle (Larson and Chow 2003). We also sent a reminder to informants who had not responded after 3 weeks. The participants were asked to provide their opinion from the perspective of their whole subsidiary (not on an individual level).

In total, we collected 184 usable questionnaires, for a response rate of about 13 percent, which is similar or higher to other cross-sectional B2B studies, published 
in top-tier journals (e.g., Frels et al. 2003; Lam et al. 2004; Srinivasan et al. 2005). To assess nonresponse bias, we compared the means of all our latent variables for early and late respondents (Armstrong and Overton 1977). We found no differences at a 5\% significance level, indicating that nonresponse bias is not a major issue in our data (see "Appendix A").

40.8 percent of the surveyed subsidiaries were located in central Europe, such as Bulgaria, Hungary, the Czech Republic, and Poland, as well as Germany, France, and the Netherlands. Furthermore, 14.2 percent of the subsidiaries were located in northern Europe (i.e., Denmark, Estonia, Ireland, Sweden) and 15.4 percent in south-west Europe (i.e., Portugal, Spain). The response rates for each country are proportional to the share of questionnaires we sent out to each country. Most key informants served as managing directors (44 percent) or sales managers (38.8 percent); thus, we succeeded in obtaining information from local subsidiary managers about sales-related issues.

\subsection{Description of measures}

When available, we used well-established scales and adapted them to our study context. The measures appear in the "Appendix A".

\subsubsection{Economic, cultural and market environment}

For the economic environment, we relied on the Human Development Index (HDI; United Nations Development Program, 2010), which offered a comparative measure of life expectancy, literacy, education, and standards of living for countries worldwide. The HDI is measured on a national level, which allowed us to assign the HDI of the subsidiary's location to each respondent. To reflect the cultural environment, we relied on the masculinity/ femininity dimension of Hofstede's (1980) framework. Hofstede's indices were available for all countries in which the sales units were located. We assigned the respective masculinity/femininity index to each respondent. We represented market environment by market uncertainty (Kumar et al. 1995). Since market uncertainty is mainly influenced by a company's current economic situation (e.g., recent investments made, competitive positioning etc.), we measured market uncertainty as a self-reported measure by means of a semantic differential scale. Salespeople indicated their market perception on a seven-point scale between two polar adjectives (i.e., stable vs. volatile industry, accurate vs. inaccurate sales forecasts, predictable vs. unpredictable market development).

\subsubsection{Types of control}

We measured process control and output control with a seven-point Likert scale adapted from Jaworski and MacInnis (1989). 


\subsubsection{Outcomes}

Psychological and economical outcomes indicate the outcome effects. Satisfaction, as a psychological outcome, includes overall satisfaction with the relationship and perceived interest and concern received by the manufacturer (Gassenheimer and Ramsey 1994). In addition, selling performance serves as an economical outcome, providing information about evaluations of the achieved sales quantity and sales targets relative to other sales units (Sujan et al. 1994). Adapted from Cravens et al. (1993), our scale employed an 11-point Likert scale, from "do not agree" to "totally agree".

We gathered the independent and dependent data from the same source. In order to overcome the potential of common method bias, we followed the advice of Podsakoff et al. (2003) ex ante (e.g., survey construction, anonymity, pretests). We ensured that the items and questionnaire were as concise as possible. Second, we separated the measurement of predictor and criterion variables in the questionnaire and used different scale types, response formats, and scale endpoints. Third, respondent's answers were anonymous. Fourth, with our pretests, we reduced any comprehension problems prior to the survey.

Furthermore, we controlled for common-method variance by using Harman's single-factor test. Neither a single factor emerged nor did one general factor account for the majority of the variance. Finally, we included a latent method factor in Model 1 , with paths leading to each of the indicator variables. All the paths to the indicator variables from their respective latent constructs continued to be significant. The relationships between the latent factors were altered slightly but not substantively, and they remained statistically the same in terms of their significance compared with the model without the latent method factor. Adding the latent method factor to Model 2 similarly did not produce any major changes in model fit. As a result, the influence of common method bias appears negligible.

\section{Results}

\subsection{Measure assessment}

All scales indicate solid psychometric properties, demonstrating a high reliability and validity of the measurements. All factor loadings demonstrated a positive sign and substantial magnitude ( $>0.5$, Kline 2005). Three indicators ("stable/volatile industry volume," "exceeding sales targets and objectives," and "overall profitability with manufacturer's products") showed indicator reliabilities slightly below the 0.4 threshold but remained in the model to increase the content validity of the measurement. Each factor loading was significant $(p<0.01)$, in support of convergent validity.

We assessed the internal consistency according to construct reliability and average variance extracted. All construct reliabilities were above the 0.6 threshold (Bagozzi and Yi 1988), and the average variance extracted for each factor showed a solid result far above the 0.5 threshold suggested by Netemeyer et al. 
Table 2 Matrix of HTMT ratio of correlations of all latent constructs

\begin{tabular}{|c|c|c|c|c|c|}
\hline Variables & 1 & 2 & 3 & 4 & 5 \\
\hline 1. Market uncertainty & - & & & & \\
\hline 2. Output control & 0.54 & - & & & \\
\hline 3. Process control & 0.49 & 0.59 & - & & \\
\hline $\begin{array}{l}\text { 4. Satisfaction with the } \\
\text { relationship with the head- } \\
\text { quarters }\end{array}$ & 0.59 & 0.28 & 0.20 & - & \\
\hline 5. Selling performance & 0.50 & .07 & 0.07 & 0.06 & - \\
\hline
\end{tabular}

(2003). As suggested by Bagozzi and Phillips (1982), we assessed discriminant validity with a series of chi-square difference tests across all possible pairs of factors. The chi-square difference statistic confirmed discriminant validity among the separate constructs. Thus, we found substantial evidence of convergent and discriminant validity, as well as internal consistency, for the proposed measures. We also calculated the heterotrait-monotrait (HTMT) ratio of correlations as an additional measure for discriminant validity (Franke and Sarstedt 2019; Henseler et al. 2015). The HTMT ratio of correlations for all latent constructs does not exceed the critical threshold of 0.85 , providing additional support for discriminant validity. The results of the HTMT are provided in Table 2.

To control for multicollinearity, we calculated the variance inflation factors of the variables. The variables in our study yielded values between 1.003 and 1.064 , indicating that there are no problems with multicollinearity (Kleinbaum et al. 1998).

The confirmatory factor analysis of the measurement model, conducted using Mplus 4.1, indicated a good overall fit of the model with the data $\left(\chi^{2}(94)=108.3, \mathrm{RMSEA}=0.03, \mathrm{CFI}=0.99, \mathrm{TLI}=0.98, \mathrm{SRMR}=0.04\right)$. Table 3 provides detailed information on the measurement properties of our variables as well as the model fit statistics. Table 4 provides an overview of the correlation matrix of the constructs and indicators included in this study.

\subsection{Analytical procedure}

We use structural equation modeling to test the hypothesized main and moderating effects. In a first step, we test the direct effects of local environmental factors on output and process control as well as the effects of output and process control on our outcome variables (model 1 and 2). In a second step, we test the direct effects of the environmental factors on psychological and economical outcomes. In a third step, we compare both models with a third baseline model that only contains the direct effects of environmental factors on marketing and sales controls, and the effects of marketing and sales controls on psychological and economical outcomes. We compare all three models by using Bayesian information criteria (BIC) and Akaike weights. 


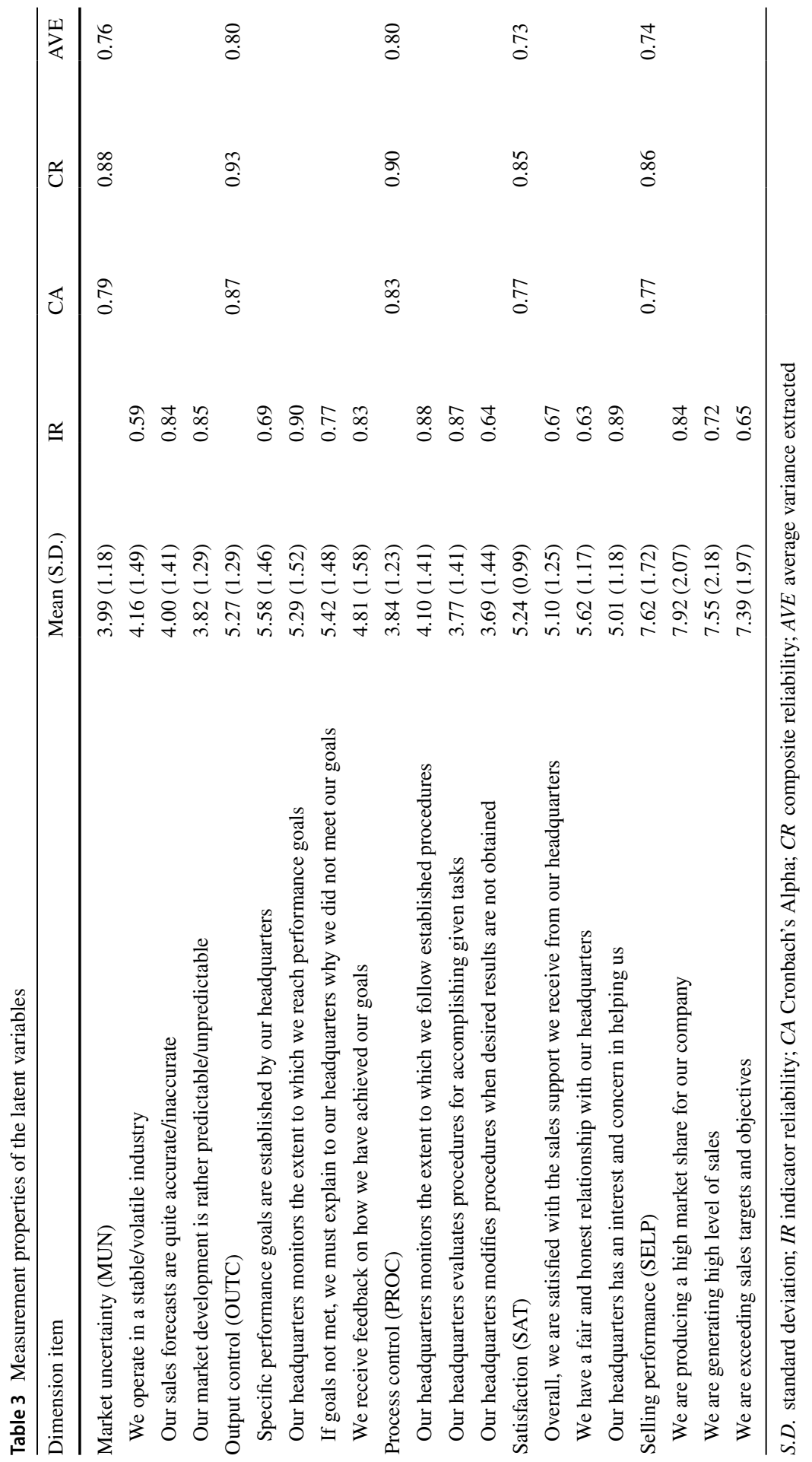


Table 4 Correlation matrix of latent and manifest variables

\begin{tabular}{|c|c|c|c|c|c|c|c|}
\hline Variables & 1 & 2 & 3 & 4 & 5 & 6 & 7 \\
\hline 1. Human development indicator (HDI) & 1.00 & & & & & & \\
\hline 2. Hofstedian masculinity & 0.04 & 1.00 & & & & & \\
\hline 3. Market uncertainty & $-0.24 * *$ & 0.03 & 1.00 & & & & \\
\hline 4. Output control & 0.07 & $0.16^{*}$ & $-0.20 * *$ & 1.00 & & & \\
\hline 5. Process control & -0.01 & 0.06 & 0.04 & $0.45^{* *}$ & 1.00 & & \\
\hline $\begin{array}{l}\text { 6. Satisfaction with the relationship } \\
\text { with the headquarters }\end{array}$ & -0.11 & -0.08 & $-0.26 * *$ & $0.18^{*}$ & 0.07 & 1.00 & \\
\hline 7. Selling performance & $-0.18 *$ & -0.05 & -0.11 & -0.04 & 0.00 & -0.00 & 1.00 \\
\hline
\end{tabular}

*Correlation is significant at the .05 level (two-tailed)

**Correlation is significant at the .01 level (two-tailed)

\subsection{Test of direct and moderating effects}

The proposed direct effects of the two control types on outcome variables showed different results. Output control exerted a positive effect on psychological outcomes, but we did not find significant effects on economical outcomes. Thus, we find support for hypothesis 1 a but not for hypothesis $1 \mathrm{~b}$. Specifically, output control by headquarters led to increasing satisfaction with the manufacturer relationship (Model 1 $\gamma=0.25, p<0.01$ ), but its effect on selling performance was not significant. Regarding the effect of process control on psychological and economical outcomes, we found no significant effects.

The structural model provided mixed support for the hypotheses regarding the direct effect of the local environmental context on output control. Hypothesis $3 \mathrm{a}$ and $\mathrm{b}$ are rejected, because economic environment showed no significant effects on output and process control.

In support of hypothesis $4 \mathrm{a}$, masculinity shows a significant positive effect on output control (Hypothesis $4 a$, Model $1 \gamma=0.169, p<0.01$ ), but no significant effect on process control. Therefore, hypothesis $4 \mathrm{~b}$ is rejected.

Market uncertainty shows a significant negative influence on output control (Hypothesis 5a, Model $1 \gamma=-0.253, p<0.01$ ), but no significant effect on process control. Therefore, hypothesis $5 \mathrm{a}$ can be supported, while hypothesis $5 \mathrm{~b}$ is rejected.

To our surprise, none of the moderating effects of the local environment affect the relationship between marketing and sales controls and outcome variables; that is, all the predicted moderating relationships were not significant. Thus, we reject Hypothesis 9,10 and 11 . Table 5 provides an overview of our results.

In the rival model (Model 2), we tested the direct effects of local environment on psychological and economical outcome variables. In line with hypothesis $6 \mathrm{a}$, a more developed economic environment led to less satisfaction with the manufacturer relationship (Hypothesis 6a, Model $2 \gamma=-0.237, p<0.01$ ). In contrast to hypothesis $6 \mathrm{~b}$, we find a negative effect of economic environment on performance (Hypothesis $6 \mathrm{~b}$, Model $2 \gamma=-0.219, p<0.01$ ). The cultural environment (masculinity) had no significant effect on satisfaction and performance, rejecting hypothesis $7 \mathrm{a}$ and $\mathrm{b}$. 
Table 5 Path coefficients for Models 1, 2, and 3

\begin{tabular}{lll}
\hline $\begin{array}{l}\text { Hypothesized Effects (standardized } \\
\text { estimates) }\end{array}$ & $\begin{array}{l}\text { Model 1: } \\
\text { moderating } \\
\text { effects }\end{array}$ & Model 2: direct effects $\quad$ Model 3: basic effects \\
& &
\end{tabular}

\begin{tabular}{|c|c|c|c|}
\hline \multicolumn{4}{|l|}{ Basic effects } \\
\hline HDI $\rightarrow$ Output control & 0.018 & 0.020 & 0.014 \\
\hline HSM $\rightarrow$ Output control & $0.169 * *$ & $0.169^{*}$ & $0.166^{* *}$ \\
\hline MUNC $\rightarrow$ Output control & $-0.253^{* *}$ & $-0.244 * *$ & $-0.250 * *$ \\
\hline HDI $\rightarrow$ Process control & 0.001 & -0.001 & -0.001 \\
\hline HSM $\rightarrow$ Process control & 0.082 & 0.083 & 0.082 \\
\hline MUNC $\rightarrow$ Process control & 0.052 & 0.047 & 0.048 \\
\hline $\begin{array}{l}\text { Output control } \rightarrow \text { Selling perfor- } \\
\text { mance }\end{array}$ & -0.173 & -0.128 & -0.071 \\
\hline Output control $\rightarrow$ Satisfaction & $0.250^{* *}$ & $0.224 *$ & $0.309 * *$ \\
\hline $\begin{array}{l}\text { Process control } \rightarrow \text { Selling perfor- } \\
\text { mance }\end{array}$ & 0.038 & 0.068 & 0.021 \\
\hline Process control $\rightarrow$ Satisfaction & 0.100 & 0.080 & 0.020 \\
\hline \multicolumn{4}{|l|}{ Direct effects } \\
\hline HDI $\rightarrow$ Selling performance & $-0.191 *$ & $-0.219 * *$ & \\
\hline HDI $\rightarrow$ Satisfaction & $-0.252^{* *}$ & $-0.237 * *$ & \\
\hline HSM $\rightarrow$ Selling performance & -0.046 & -0.035 & \\
\hline HSM $\rightarrow$ Satisfaction & -0.075 & -0.092 & \\
\hline MUNC $\rightarrow$ Selling performance & $-0.223^{* *}$ & $-0.223^{* *}$ & \\
\hline MUNC $\rightarrow$ Satisfaction & $-0.321^{* *}$ & $-0.308 * *$ & \\
\hline \multicolumn{4}{|l|}{ Interaction effects } \\
\hline hdiXoutc $\rightarrow$ Selling performance & 0.024 & & \\
\hline hdiXoutc $\rightarrow$ Satisfaction & -0.023 & & \\
\hline hsmXoutc $\rightarrow$ Selling performance & -0.129 & & \\
\hline hsmXoutc $\rightarrow$ Satisfaction & 0.077 & & \\
\hline muncXoutc $\rightarrow$ Selling performance & -0.114 & & \\
\hline muncXoutc $\rightarrow$ Satisfaction & -0.047 & & \\
\hline hdiXproc $\rightarrow$ Selling performance & -0.056 & & \\
\hline hdiXproc $\rightarrow$ Satisfaction & 0.042 & & \\
\hline hsmXproc $\rightarrow$ Selling performance & -0.064 & & \\
\hline hsmXproc $\rightarrow$ Satisfaction & 0.140 & & \\
\hline muncXproc $\rightarrow$ Selling performance & -0.021 & & \\
\hline muncXproc $\rightarrow$ Satisfaction & 0.046 & & \\
\hline
\end{tabular}

HDI Human Development Index, HSM masculinity/femininity, MUNC market uncertainty

$\mathrm{R}_{\text {output control }}^{2}=.08^{*} ; \mathrm{R}_{\text {process control }}^{2}=.01$, n.s.; $\mathrm{R}_{\text {satisfaction }}^{2}=.16^{* *} ; \mathrm{R}_{\text {performance }}^{2}=.09, \mathrm{n} . \mathrm{s}$

*Significant at $95 \%$. **Significant at $99 \%$

Consistent with hypotheses 8 , we find a significant negative effect of market uncertainty on the level of satisfaction and performance (Hypothesis 7a, Model 2: $\gamma=-$ $0.308, p<0.01$; hypothesis $7 \mathrm{~b}$, Model 2: $\gamma=-0.223, p<0.01$ ). 
Table 6 Information criteria and ranks for competitive models

\begin{tabular}{llll}
\hline Information criteria & Model 1 & Model 2 & Model 3 \\
\hline Effects included & Moderating & Direct & $\begin{array}{c}\text { No mod- } \\
\text { erator, no } \\
\text { direct }\end{array}$ \\
Chi-square/df & & & 1.41 \\
Confirmatory fit index & 2.23 & 1.22 & 0.96 \\
Tucker-Lewis index & 0.89 & 0.98 & 0.95 \\
Bayesian information crit rion (BIC) & 0.86 & 0.97 & $10,955.13$ \\
Sample size-adjusted BIC & $14,695.01$ & $10,958.72$ & $10,758.76$ \\
Sample size-adjusted BIC rank & $14,422.64$ & $10,743.36$ & 2 \\
Akaike information criterion (AIC) & 3 & 1 & $10,756.48$ \\
$\Delta$ (AIC-AIC min & $14,419.47$ & $10,740.85$ & 15.63 \\
Akaike weights & $3,678.47$ & 0 & 0.0004 \\
\hline
\end{tabular}

\subsection{Comparison of rival models}

An important indicator of a conceptual model's quality in addition to hypotheses testing results is its fit with empirical data in comparison with the fit of rival models (Bagozzi and Yi 1988). In our international setting, we question whether the local context variables (e.g., local market uncertainty) affect individual and organizational outcomes in a direct, mediated, or moderating way. But alternatively, the direct, mediating, and moderating relationships might combine to affect any given outcome variables. We test these alternative propositions in an additional rival model (see Fig. 1): Model 1 contains the moderating effect of the environmental context, Model 2 assumes a direct effect of the environmental context on psychological and economical outcomes, and Model 3 serves as a baseline, without any direct effects of environmental context on psychological and economical outcomes or moderating effects.

Again, we estimated the proposed main effects in all three structural models. For the selection, we calculated the sample size-adjusted Bayesian information criteria (BIC) and the Akaike weights (Danks et al. 2020). Several competing models may be ranked according to their BIC, such that the one with the lowest BIC is the best (Akaike 1974). As we show in Table 6, the overall fit described by the sample size-adjusted BIC is best for Model 2, which contains the direct effect of the environmental context on psychological and economical outcomes. Model 1, including both moderating and direct effects of the environmental context, exhibited the highest residual sum of squares and the lowest rank for the adjusted BIC. The baseline Model 3 ranked second place for the sample size-adjusted BIC.

We also calculated the Akaike weights, which can be described as conditional probabilities for models (Danks et al. 2020). The results confirm that Model 2 (Akaike weight 0.9996) appears to be the superior model compared to Model 1 and Model 3 (see also Table 6). These results indicate that economical context is rather a 
predictor of psychological and economical outcomes, rather than a moderating factor on the effect of control mechanisms on psychological and economical outcomes.

\section{Discussion}

\subsection{Theoretical implications}

Previous research has focused predominantly on how headquarters can adapt their general management practices to local boundary conditions of international subsidiaries. However, the influence of a firm's economic and cultural environment on marketing and sales control mechanisms has not been thoroughly examined yet. This paper helps to understand how MNCs apply marketing and sales controls in international headquarters-subsidiaries relationships. In order to substantiate the findings from our empirical study and derive further explanatory approaches, we conducted an additional interview with the global sales director of a world market leader in the project machinery business, representing the target group of our quantitative empirical study.

Our first research question investigated the influence of environmental factors on the configuration of marketing and sales control systems in MNCs. The results of our empirical study show that especially the degree of output control varies according to environmental factors. Our results show a negative effect of market uncertainty on output control, indicating that output control appears to be less dominant in uncertain environments. Our interview partner confirms that in uncertain environments, business outcomes are difficult to assess and, thus, impede the formulation of clear and realistic business goals. Moreover, our results indicate that high degrees of output control are more dominant in sales units in high masculine cultures. Our interview partner also supports this finding and adds that highly masculine cultures show a higher degree of performance orientation and, thus, may prefer control mechanisms that are based on clear performance goals.

Our second research question referred to the effect of marketing and sales control mechanisms on economical and psychological outcomes in international subsidiaries. Prior research shows contradicting results on the direct effects of sales controls on psychological and economical outcome variables (Katsikeas et al. 2018). While some studies found significant direct effects of output and process control on psychological and economical outcomes (e.g., Evans et al. 2007; Cravens et al. 2004), other studies show either no or only indirect effects of sales controls on the respective outcome variables (e.g., Miao and Evans 2014; Katsikeas et al. 2018). Our study indicates that the direct effects of output and process control on psychological and economical outcomes is rather limited. Our empirical results show that process control neither had a direct effect on selling performance nor on satisfaction with the relationship with the headquarters. Process control requires very frequent and close interactions in order to monitor the behavioral performance of the subsidiaries. Therefore, it may be possible that due to the rather large distance between headquarters and subsidiaries, these frequent interactions are rather not possible, limiting the potential influence of process control on performance. Moreover, the results show 
a significant positive direct effect of output control on our psychological outcome satisfaction with the relationship with the headquarters. These results indicate that while output control appears to promote the relationship quality between headquarters and subsidiaries, it is not effective for promoting performance of international subsidiaries. Our interview partner provides a possible explanation and states that international subsidiaries often appreciate higher degrees of autonomy, supporting the positive effect of output control on satisfaction with the relationship with the headquarters. Moreover, the interview reveals a possible explanation for the missing link between output control and performance. Although our interview partner perceives output-based controls as effective mechanisms for controlling international subsidiaries, he also confirms that performance measures are rather susceptible for industry-specific developments, such as economic developments or volatile raw material prices (see also Kouvelis et al. 2018). If companies do not account for these developments when configuring output-based controlling mechanisms, the effectiveness of these mechanisms may be severely limited.

Our third research question investigated the influence of environmental factors on the effectiveness of marketing and sales controls in international headquarterssubsidiary relationships. Prior research has largely ignored to analyze the influence of environmental factors on formal control mechanisms. We contribute to previous research by empirically testing Jaworski's (1988) model in an international context. Our study shows that Jaworski's model suffers in comparison with a model including solely direct effects. The lack of any significant moderating effect indicates that the direct effects of output and process control on economic and psychological outcomes may not be contingent on the local environment. A possible explanation may be that factors stemming from an individual organizational culture may overlap the potential influence of general environmental factors and, therefore, undermine potential moderating effects of environmental factors on the effectiveness of marketing and sales controls. In contrast to our study results, our interview partner observes certain differences between international subsidiaries. However, he confirms that these differences became increasingly smaller over the past years and provides a possible explanation for this trend as during the last years, MNCs established uniform management practices and tools for subsidiaries across the world and, thereby, increased the degree of professionalization worldwide. Furthermore, management education across the world has significantly improved and has been standardized over the past years. Both developments may equalize the influence of local environment on a company's success and, therefore, may explain the non-significant moderating effects of environmental factors on the effectiveness of marketing and sales controls.

\subsection{Managerial implications}

The evidence from our empirical study suggests that headquarters should be aware of the potential existence of multiple predictors of sales unit performance. If markets provide good economic conditions for business operations, various competitors are attracted to these markets, and technological progress continues to develop rapidly. 
In such competitive, dynamic markets, sales units likely expect supporting activities and guiding mechanisms from headquarters, not only when the market environment is insecure, but also when it is highly developed. These expectations resonate with the negative effects of both HDI and market uncertainty on selling performance.

Headquarters should also be aware that sales subsidiaries pin their expectations on the relationship with the manufacturer, depending on the local environment. In particular, a highly developed economy and an uncertain market environment have a negative influence on the relationship satisfaction with the headquarters. Due to these direct effects, headquarters should consider these environmental factors in order to maintain an effective relationship with their subsidiaries.

Moreover, for headquarters with sales units located in different local environments, we suggest that before implementing controlling mechanism, they should assess individual characteristics of the cultural environment. Although, the effectiveness of both, output and process control, is not contingent on environmental factors, our results indicate that performance-oriented cultures tend to favor an outputbased control system, leading to a higher satisfaction with the relationship with the headquarters.

\subsection{Limitations and further research}

There are several limitations of our study that require further investigation in the future. First, the results derived from the new model were tested only for formal types of control. Whether an economic performance effect can be achieved through informal control types or some other combination and even whether informal controls actually emerge as an effective tool within headquarters-subsidiary relationships remains unclear and should be the topic of further research.

The second limitation is related to the sample of the empirical study. Our sample was selected from among manufacturers of industrial goods headquartered in Switzerland. To avoid the influence of the specific Swiss culture, comparisons across further home markets should be a next step. Moreover, it may also be possible that difference between foreign and domestic markets are relevant for the effectiveness of marketing controls. Further research may address this issue by focusing on the influence of cultural differences between headquarters and international subsidiaries. Another issue connected to the sample of the paper is a certain lack of transparency of the sample. Our sample structure contains several crucial information, such as industry and location of the subsidiaries, however, some important information are missing. Although we assured that the participants are marketing and sales managers from a higher management level of the respective subsidiaries, we do not have further information on the specific position the participants are holding or on the level of professional experience. This lack of transparency may limit the generalizability of our findings.

Third, previous research indicates that industry and organizational culture may also influence management practices (e.g., Gordon 1991; Nakata and Sivakumar 2001; Williams and van Triest 2009). Therefore, further research may test the effectiveness of sales control systems in other industrial settings in order to account for differences in 
industry cultures and, thereby, further improve the generalizability of our results. Further research may also include additional environmental variables to account for other potential external factors on the effectiveness of control mechanisms.

Finally, to reduce concerns associated with common method variance, further research also might avoid single sources for the local environment context, market marketing control, and objective performance variables. Although our response rate of 13 percent is similar to other cross-sectional B2B studies, results should be treated with caution. Further studies should aim for larger sample sizes in order to improve the generalizability of the results.

\section{Appendix A: Differences of construct means between early and late respondents}

\begin{tabular}{|c|c|c|c|}
\hline \multirow[t]{2}{*}{ Variables } & \multicolumn{2}{|l|}{ Means } & \multirow{2}{*}{$\begin{array}{l}\text { Difference test } \\
\text { F value (level of significance) }\end{array}$} \\
\hline & $\begin{array}{l}\text { Early respond- } \\
\text { ents }\end{array}$ & Late respondents & \\
\hline Market uncertainty & 4.14 & 3.85 & 2.833 (0.09, n.s.) \\
\hline Output control & 5.29 & 5.25 & $0.046(0.83$, n.s. $)$ \\
\hline Process control & 3.80 & 3.89 & 0.233 (0.64, n.s.) \\
\hline Satisfaction & 5.32 & 5.17 & $1.086(0.30$, n.s. $)$ \\
\hline Selling performance & 7.77 & 7.47 & $1.328(0.25$, n.s. $)$ \\
\hline
\end{tabular}

We did not include the measures of economic and cultural environment into this analysis, because the means of those variables were dependent on when the headquarters forwarded the survey to the subsidiaries and not when the participants decided to take part in the survey

n.s. not significant

Author contributions All authors are contributed to an equal degree.

Funding Open Access funding enabled and organized by Projekt DEAL.

Availability of data and material Data are available on request.

Code availability Not applicable.

\section{Declarations}

Conflict of interest Not applicable.

Open Access This article is licensed under a Creative Commons Attribution 4.0 International License, which permits use, sharing, adaptation, distribution and reproduction in any medium or format, as long as you give appropriate credit to the original author(s) and the source, provide a link to the Creative Commons licence, and indicate if changes were made. The images or other third party material in this article are included in the article's Creative Commons licence, unless indicated otherwise in a credit line to the material. If material is not included in the article's Creative Commons licence and your intended use is not permitted by statutory regulation or exceeds the permitted use, you will need to obtain permission 
directly from the copyright holder. To view a copy of this licence, visit http://creativecommons.org/licen ses/by/4.0/.

\section{References}

Akaike H (1974) A new look at the statistical model identification. IEEE Trans Autom Control 19(6):716-723

Anderson E, Oliver RL (1987) Perspectives on behavior-based versus outcome-based salesforce control systems. J Mark 51(4):76-88

Armstrong JS, Overton TS (1977) Estimating nonresponse bias in mail surveys. J Mark Res 14(3):396-402

Arnold D (2000) Seven rules of international distribution. Harv Bus Rev 78(6):131-137

Asakawa K (2001) Organizational tension in international R\&D management: the case of Japanese firms. Res Policy 30(5):735-757

Atuahene-Gima K, Li H (2002) When does trust matter? Antecedents and contingent effects of supervisee trust on performance in selling new products in China and the United States. J Mark 66(3):61-88

Aulakh PS, Kotabe M, Sahay A (1996) Trust and performance in cross-border marketing partnerships: a behavioral approach. J Int Bus Stud 27(5):1005-1032

Bagozzi RP, Phillips LW (1982) Representing and testing organizational theories: a holistic construal. Adm Sci Q 27(3):459-489

Bagozzi RP, Yi Y (1988) On the evaluation of structural equation models. J Acad Mark Sci 16(1):74-94

Baldauf A, Cravens DW, Piercy NF (2001) Examining the consequences of sales management control strategies in European field sales organizations. Int Mark Rev 18(5):474-508. https://doi.org/10. 1108/EUM0000000006042

Batonda G, Perry CP (2003) Influence of culture on relationship development processes in overseas Chinese/Australian networks. Eur J Mark 37(11/12):1548-1574

Bello DC, Gilliland DI (1997) The effect of output controls, process controls, and flexibility on export channel performance. J Mark 61(1):22-38

Bloom M, Milkovich GT, Mitra A (2003) International compensation: learning from how managers respond to variations in local host contexts. Int J Hum Resour Manag 14(8):1350-1367

Bonoma TV (1985) Case research in marketing: opportunities, problems, and a process. J Mark Res 22(2):199-208

Bourgeois LJ III (1980) Strategy and environment: a conceptual integration. Acad Manag Rev 5(1):25-39

Brown SP, Peterson RA (1993) Antecedents and consequences of salesperson job satisfaction: meta-analysis and assessment of causal effects. J Mark Res 30(1):63-77

Brown SP, Peterson RA (1994) The effect of effort on sales performance and job satisfaction. J Mark 58(2):70-80

Brown SP, Cron WL, Slocum JW (1998) Effects of trait competitiveness and perceived intraorganizational competition on salesperson goal setting and performance. J Mark 62(4):88-98

Burke MC (1984) Strategic choice and marketing managers: an examination of business-level marketing objectives. J Mark Res 21(4):345-359

Calori R, Lubatkin M, Very P (1994) Control mechanisms in cross-border acquisitions: an international comparison. Organ Stud 15(3):361-379

Celly KS, Frazier GL (1996) Outcome-based and behavior-based coordination efforts in channel relationships. J Mark Res 33(2):200-210

Challagalla GN, Shervani TA (1996) Dimensions and types of supervisory control: effects on salesperson performance and satisfaction. J Mark 60(1):89-105

Chen B, Vansteenkiste M, Beyers W, Boone L, Deci EL, Van der Kaap-Deeder J, Duriez B, Lens W, Matos L, Mouratidis A, Ryan RM, Sheldon KM, Soenens B, Van Petegem S, Verstuyf J (2015) Basic psychological need satisfaction, need frustration, and need strength across four cultures. Motiv Emot 39(2):216-236

Chini T, Ambos B, Wehle K (2005) The headquarters-subsidiaries trench: tracing perception gaps within the multinational corporation. Eur Manag J 23(2):145-153 
Chirkov V, Ryan RM, Kim Y, Kaplan U (2003) Differentiating autonomy from individualism and independence: a self-determination theory perspective on internalization of cultural orientations and well-being. J Pers Soc Psychol 84(1):97

Cravens DW, Ingram TN, LaForge RW, Young CE (1993) Behavior-based and outcome-based sales force control system. J Mark 57(4):47-60

Cravens DW, Lassk FG, Low GS, Marshall GW, Moncrief WC (2004) Formal and informal management control combinations in sales organizations-The impact on salesperson consequences. J Bus Res 57(3):241-248

Danks NP, Sharma PN, Sarstedt M (2020) Model selection uncertainty and multimodel inference in partial least squares structural equation modeling (PLS-SEM). J Bus Res 113:13-24

Desai M (1991) Human development, concepts and measurement. Eur Econ Rev 35(2-3):350-357

Deshpande R, Webster FE Jr (1989) Organizational culture and marketing: defining the research agenda. J Mark 53(1):1-15

Duncan RB (1972) Characteristics of organizational environment and perceived environmental uncertainty. Adm Sci Q 17(3):313-327

Dwyer FR (1980) Channel-member satisfaction: laboratory insights. J Retail 56(2):45-65

Dwyer FR, Oh S (1987) Output sector munificence effects on the internal political economy of marketing channels. J Mark Res 24(4):347-358

Eisenhardt KM (1985) Control: organizational and economic approaches. Manage Sci 31(2):134-149

Evans J, Mavondo FT (2002) Psychic distance and organizational performance: an empirical examination of international retailing operations. J Int Bus Stud 33(3):515-532

Evans KR, Landry TD, Li PC, Zou S (2007) How sales controls affect job-related outcomes: the role of organizational sales-related psychological climate perceptions. J Acad Mark Sci 35(3):445-459

Fahey L, Narayanan V (1986) Macroenvironmental analysis for strategic environment. West Publishing, St. Paul

Fang E, Evans KR, Zou S (2005) The moderating effect of goal-setting characteristics on the sales control systems-job performance relationship. J Bus Res 58(9):1214-1222

Fang Y, Wade M, Delios A, Beamish PW (2013) An exploration of multinational enterprise knowledge resources and foreign subsidiary performance. J World Bus 48(1):30-38. https://doi.org/10.1016/j. jwb.2012.06.004

Franke G, Sarstedt M (2019) Heuristics versus statistics in discriminant validity testing: a comparison of four procedures. Internet Res 29(3):430-447

Frels JK, Shervani T, Srivastava RK (2003) The integrated networks model: explaining resource allocations in network markets. J Mark 67(1):29-45

Futrell CM, Parasuraman A (1984) The relationship of satisfaction and performance to salesforce turnover. J Mark 48(4):33-40

Gassenheimer JB, Ramsey R (1994) The impact of dependence on dealer satisfaction: a comparison of reseller-supplier relationships. J Retail 70(3):253-266

Gencturk EF, Aulakh PS (1995) The use of process and output controls in foreign markets. J Int Bus Stud 26(4):755-786

Gordon GG (1991) Industry determinants of organizational culture. Acad Manag Rev 16(2):396-415

Govindarajan V (1984) Appropriateness of accounting data in performance evaluation: an empirical examination of environmental uncertainty as intervening variable. Account Organ Soc 9(2):125-135

Grewal R, Kumar A, Mallapragada G, Saini A (2013) Marketing channels in foreign markets: control mechanisms and the moderating role of multinational corporation headquarters-subsidiary relationship. J Mark Res 50(3):378-398. https://doi.org/10.1509/jmr.11.0487

Henseler J, Ringle CM, Sarstedt M (2015) A new criterion for assessing discriminant validity in variance-based structural equation modeling. J Acad Mark Sci 43(1):115-135

Hill JS, Still RR, Boya ÜO (1991) Managing the multinational sales force. Int Mark Rev 8(1):19-31

Hofstede G (1980) Cultural consequences: international differences in work related values. Sage Publications, Beverly Hills

Hofstede G (1983) National cultures in four dimensions: a research-based theory of cultural differences among nations. Int Stud Manag Organ 13(1-2):46-74

Hofstede G (1994) Management scientists are human. Manag Sci 40(1):4-13

Homburg C, Prigge J-K (2014) Exploring subsidiary desire for autonomy: a conceptual framework and empirical findings. J Int Mark 22(4):21-43. https://doi.org/10.1509/jim.14.0026 
Hoppe MH (1998) Validating the masculinity/femininity dimension on elites from 19 countries. In: Hofstede G (ed) Masculinity and femininity: the taboo dimension of national cultures. Sage Publications, Thousand Oaks

Jaworski BJ (1988) Toward a theory of marketing control: environmental context, control types, and consequences. J Mark 52(3):23-39

Jaworski BJ, Kohli SK (1991) Supervisory feedback: alternative types and their impact on salespeople's performance and satisfaction. J Mark Res 28:190-201

Jaworski BJ, MacInnis DJ (1989) Marketing job and management controls: toward a framework. J Mark Res 26(4):406-419

Jaworski BJ, Stathakopoulos V, Krishnan HS (1993) Control combinations in marketing: conceptual framework and empirical evidence. J Mark 57:57-69

Johnson RA, Hoskisson RE, Hitt MA (1993) Board of director involvement in restructuring: the effect of board versus managerial controls and characteristics. Strateg Manag J 14(3):33-50

Johnson JL, Cullen JB, Sakano T, Takenouchi H (1996) Setting the stage for trust and strategic integration in Japanese-U.S. cooperative alliances. J Int Bus Stud 27(5):981-1004

Katsikeas CS, Auh S, Spyropoulou S, Menguc B (2018) Unpacking the relationship between sales control and salesperson performance: a regulatory fit perspective. J Mark 82(3):45-69

Kim K, Oh C (2002) On distributor commitment in marketing channels for industrial products: contrast between the United States and Japan. J Int Mark 10(1):72-107

Klein S, Frazier GL, Roth VJ (1990) A transaction cost analysis model of channel integration in international markets. J Mark Res 27(2):196-208

Kleinbaum DG, Kupper LL, Muller KE, Nizam A (1998) Applied regression analysis and other multivariate methods. Duxbury Press, Pacific Grove

Kline RB (2005) Principles and practice of structural equation modeling. The Guilford Press, New York

Kohli AK, Shervani TA, Challagalla GN (1998) Learning and performance orientation of salespeople: the role of supervisors. J Mark Res 35(2):263-274

Kouvelis P, Turcic D, Zhao W (2018) Supply chain contracting in environments with volatile input prices and frictions. Manuf Serv Oper Manag 20(1):130-146

Krafft M (1999) An empirical investigation of the antecedents of sales force control systems. J Mark 63:120-134

Krishnan BC, Netemeyer RG, Boles JS (2002) Self-efficacy, competitiveness, and effort as antecedents of salesperson performance. J Pers Sell Sales Manag 22(4):285-295

Kumar N, Stern LW, Anderson JC (1993) Conducting interorganizational research using key informants. Acad Manag J 36(6):1633-1651

Kumar N, Scheer LK, Steenkamp J-BEM (1995) The effects of supplier fairness on vulnerable resellers. J Mark Res 32(1):54-65

Kumar V, Sharma A, Shah R, Rajan B (2013) Establishing profitable customer loyalty for multinational companies in the emerging economies: a conceptual framework. J Int Mark 21(1):57-80

Lam SY, Shankar V, Erramilli MK, Murthy B (2004) Customer value, satisfaction, loyalty, and switching costs: an illustration from a business-to-business service context. J Acad Mark Sci 32(3):293-311

Larson PD, Chow G (2003) Total cost/response rate trade-offs in mail survey research: Impact of follow-up mailings and monetary incentives. Ind Mark Manag 32(7):533-537

Lebas M, Weigenstein J (1986) Management control: the roles of rules, markets and culture. J Manage Stud 23(3):259-272

Leblebici H, Salancik GR (1981) Effects of environmental uncertainty on information and decision processes in banks. Adm Sci Q 26(4):578-596

Leonidou LC, Katsikeas CS, Hadjimarcou J (2002) Executive insights: building successful export business relationships: a behavioral perspective. J Int Mark 10(3):96-115

Lindholm N (2000) National culture and performance management in MNC subsidiaries. Int Stud Manag Organ 29(4):45-66

Locke EA, Latham GP (1990) Work motivation and satisfaction: light at the end of the tunnel. Psychol Sci 1(4):240-246

Luo Y, Liu Y, Zhang L, Huang Y (2011) A taxonomy of control mechanisms and effects on channel cooperation in China. J Acad Mark Sci 39(2):307-326

Magnusson P, Peterson R, Westjohn SA (2014) The influence of national cultural values on the use of rewards alignment to improve sales collaboration. Int Mark Rev 31(1):30-50 
Mascarenhas B (1982) Coping with uncertainty in international business. J Int Bus Stud 13(2):87-98

Merchant KA, Van der Stede WA, Lin TW, Yu Z (2011) Performance measurement and incentive compensation: an empirical analysis and comparison of Chinese and western firms' practices. Eur Account Rev 20(4):639-667

Miao FC, Evans KR (2012) Effects of formal sales control systems: a combinatory perspective. Int J Res Mark 29:181-191

Miao FC, Evans KR (2013) The interactive effects of sales control systems on salesperson performance: a job demands-resources perspective. J Acad Mark Sci 41(1):73-90

Miao FC, Evans KR (2014) Motivating industrial salesforce with sales control systems: an interactive perspective. J Bus Res 67(6):1233-1242

Miao FC, Evans KR, Zou S (2007) The role of salesperson motivation in sales control systems: intrinsic and extrinsic motivation revisited. J Bus Res 60(5):417-425

Miller D, Friesen PH (1983) Strategy-making and environment: the third link. Strateg Manag J 4(3):221-235

Morris JH, Steers RM (1980) Structural influences on organizational commitment. J Vocat Behav 17(1):50-57

Nakata C, Sivakumar K (2001) Instituting the marketing concept in a multinational setting: the role of national culture. J Acad Mark Sci 29(3):255-276

Netemeyer RG, Bearden WO, Sharma S (2003) Scale development in the social sciences: issues and applications. Sage, Palo Alto

Nohria N, Ghoshal S (1994) Differentiated fit and shared values: alternatives for managing headquarters-subsidiary relations. Strateg Manag J 15(6):491-502

O'Donnell SW (2000) Managing foreign subsidiaries: agents of headquarters, or an interdependent network? Strateg Manag J 21(5):525-548

Oliver RL, Anderson E (1994) An empirical test of the consequences of behavior-and outcome-based sales control systems. J Mark 58(4):53-67

Ouchi WG (1979) A conceptual framework for the design of organizational control mechanisms. Manag Sci 25(9):833-848

Panagopoulos NG, Avlonitis GJ (2010) Performance implications of sales strategy: the moderating effects of leadership and environment. Int J Res Mark 27:46-56

Park WC, Zaltman G (1987) Marketing management. Dryden Press, Chicago

Podsakoff PM, MacKenzie SB, Lee J-Y, Podsakoff NP (2003) Common method biases in behavioral research: a critical review of the literature and recommended remedies. J Appl Psychol 88(5):879-903

Ramaswami SN (2002) Influence of control systems on opportunistic behaviors of salespeople: a test of gender differences. J Pers Sell Sales Manag 22(3):173-188

Rao MT, Brown CV, Perkins WC (2007) Host country resource availability and information system control mechanisms in multinational corporations: an empirical test of resource dependence theory. J Manag Inf Syst 23(4):11-28

Redding GS, Pugh DS (1986) The formal and the informal: Japanese and Chinese organization structures. In: Clegg SR, Dunphy DC, Redding GS (eds) The enterprise and management in East Asia. Hong Kong Centre of Asian Studies, The University of Hong Kong, Hong Kong

Rondinelli D, Rosen B, Drori I (2001) The struggle for strategic alignment in multinational corporations: Managing readjustment during global expansion. Eur Manag J 19(4):404-416

Rosenbloom B (1999) Marketing channels: a management view, 6th edn. Dryden Press, Fort Worth

Rosenzweig PM, Singh J (1991) Organizational environments and the multinational enterprise. Acad Manag Rev 16(2):340-361

Roth K, Nigh D (1992) The effectiveness of headquarters-subsidiary relationships: The role of coordination, control, and conflict. J Bus Res 25(4):277-301

Ryu S, Eyuboglu N (2007) The environment and its impact on satisfaction with supplier performance: an investigation of the mediating effects of control mechanisms from the perspective of the manufacturer in the USA. Ind Market Manag 36(4):458-469

Ryu S, Min S, Zushi N (2008) The moderating role of trust in manufacturer-supplier relationships. J Bus Ind Market 23(1):48-58

Sahadev S (2008) Economic satisfaction and relationship commitment in channels: The moderating role of environmental uncertainty, collaborative communication and coordination strategy. Eur J Mark 42(1/2):178-195 
Shackleton VJ, Ali AH (1990) Work-related values of managers, a test of the Hofstede model. J Cross Cult Psychol 21(1):109-118

Snodgrass CR, Grant JH (1986) Cultural influences on strategic planning and control systems. Adv Strateg Manag 4:205-228

Srinivasan R, Rangaswamy A, Lilien GL (2005) Turning adversity into advantage: Does proactive marketing during a recession pay off? Int J Res Mark 22(2):109-125

Sujan H, Weitz BA, Kumar N (1994) Learning orientation, working smart, and effective selling. J Mark 58(3):39-52

Tang L, Koveos PE (2008) A framework to update Hofstede's cultural value indices: economic dynamics and institutional stability. J Int Bus Stud 39(6):1045-1063

Taras V, Kirkman BL, Steel P (2010) Examining the impact of culture's consequences: a three-decade, multilevel, meta-analytic review of Hofstede's cultural value dimensions. J Appl Psychol 95(3):405-439

United Nations Conference on Trade and Development (UNCTAD) (2020) World Investment Report 2020: International Production Beyond the Pandemic. UNCTAD, New York

United Nations Development Program (2010) The real wealth of nations: Pathways to human development. Human Development Report 2010. Palgrave Macmillan, New York

Weitz BA, Jap SD (1995) Relationship marketing and distribution channels. J Acad Mark Sci 23(4):305-320

Wernerfelt B, Karnani A (1981) Competitive strategy under uncertainty. Strateg Manag J 8(2):187-194

Williams C, Van Triest S (2009) The impact of corporate and national cultures on decentralization in multinational corporations. Int Bus Rev 18(2):156-167

Zhang C, Cavusgil ST, Roath AS (2003) Manufacturer governance of foreign distributor relationships: do relational norms enhance competitiveness in the export market? J Int Bus Stud 34(6):550-566

Publisher's Note Springer Nature remains neutral with regard to jurisdictional claims in published maps and institutional affiliations. 